NOTES

\title{
Synthesis and Cation-Binding Property of Copolymers with Benzo-19-crown-6 Units via Cationic Cyclocopolymerizations of 1,2-Bis[2-(2-vinyloxyethoxy)ethoxy]- benzene with Phenyl Vinyl Ether, 4-Methoxystyrene, and 9-Vinylcarbazole
}

\author{
Toyoji KakUChI, ${ }^{\dagger, *}$ Toshitaka Watanabe, ${ }^{\dagger}$ Shigeyuki Matsunami, ${ }^{\dagger}$ \\ Osamu HaBA, ${ }^{\neq}$Yasushi Morimoto, ${ }^{\neq}$Takahiro UesaKA, ${ }^{\neq}$ \\ and Kazuaki YoKota ${ }^{\neq, *}$ \\ ${ }^{+}$Division of Bioscience, Graduate School of Environmental Earth Science, \\ Hokkaido University, Sapporo 060, Japan \\ * Division of Molecular Chemistry, Graduate School of Engineering, \\ Hokkaido University, Sapporo 060, Japan
}

(Received March 17, 1995)

\begin{abstract}
KEY WORDS Cyclocopolymerization / $\alpha, \omega$-Divinylether / Phenyl Vinyl Ether / 4-Methoxystyrene / 9-Vinylcarbazole / Cationic Initiator / Benzo-19-crown-6 / Cation-Binding Property / Alkali Metal Picrate /
\end{abstract}

The cyclopolymerization of an $\alpha, \omega$-bifunctional monomer ${ }^{1-9}$ and the cyclocopolymerization of it with an appropriate comonomer ${ }^{10-13}$ are facile methods for producing homo- and copolymers, respectively, with various types of crown ether units. We have studied the scope and limits of the cyclopolymerization method using, in particular, 1,2bis[2-(2-vinyloxyethoxy)ethoxy]benzene (BVEEB) as the typical $\alpha, \omega$-divinylether. For example, the homopolymerization of BVE$\mathrm{EB}^{3,4}$ and the copolymerization of BVEEB with isobutyl vinyl ether (IBVE) ${ }^{11}$ using the cationic initiator proceeded without a crosslinking reaction and the extent of cyclization in the polymers was $100 \%$. Poly(BVEEB) and poly(BVEEB-co-IBVE), i.e., poly(benzo-19crown-6) and poly[(benzo-19-crown-6)-coIBVE], showed the different cation-binding properties toward $\mathrm{K}^{+}, \mathrm{Rb}^{+}$, and $\mathrm{Cs}^{+}$depending on the mole fraction of the crown ether units. Part of our research program is to investigate the synthesis and host properties of the poly(crown ether), since it is interesting to determine if the cation-binding ability can be adjusted and improved by changing the comonomer units in the copolymeric crown ether. Therefore we have focused here on the cyclocopolymerization of $\alpha, \omega$-divinylether with the vinyl monomers except for the alkyl vinyl ether.

In this paper, we report the synthesis of the polymeric benzo-19-crown- 6 by the cationic cyclocopolymerizations of BVEEB with phenyl vinyl ether (PhVE), 4-methoxystyrene (MeO-

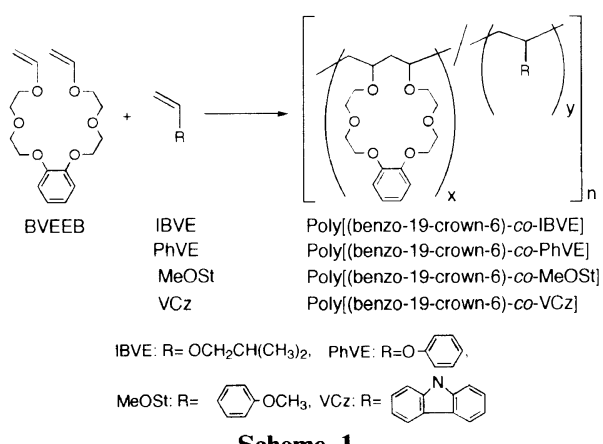

Scheme 1.

\footnotetext{
* To whom all correspondence should be addressed.
} 
$\mathrm{St}$ ), and 9-vinylcarbazole ( $\mathrm{VCz})$. The binding abilities of the synthesized crown polymers toward alkali cations were examined using the one-plate extraction method.

\section{EXPERIMENTAL}

\section{Measurements}

${ }^{1} \mathrm{H}$ NMR spectra were recorded using a Brucker MSL 400 instrument. The molecular weights of the resulting copolymers were measured by gel permeation chromatography (GPC) in tetrahydrofuran on a WATERS M45 high-performance liquid chromatography equipped with three polystyrene gel columns (Shodex KF-804L). UV spectra were obtained using a JASCO 660 UV/VIS spectrophotometer. Atomic absorption was performed with a Varian Spectra-AA 40 atomic absorption spectrometer.

\section{Materials}

Boron trifluoride etherate $\left(\mathrm{BF}_{3} \cdot \mathrm{OEt}_{2}\right)$ was purified by distillation of the commercial product under reduced pressure. Dichloromethane was purified by the usual method, and distilled over calcium hydride.

\section{Monomers}

The synthesis of 1,2-bis[2-(2-vinyloxyethoxy)ethoxy]benzene (BVEEB) was reported in a previous paper. ${ }^{3}$ Phenyl vinyl ether (PhVE) was prepared following the known literature procedure. Isobutyl vinyl ether (IBVE) and 4methoxystyrene (MeOSt) were obtained from Aldrich, and purified by distillation under reduced pressure. 9-Vinylcarbazole $(\mathrm{VCz})$ was purchased from Aldrich and used without further purification.

\section{Cyclocopolymerization}

A typical polymerization procedure is as follows: To a solution of $1.71 \mathrm{~g}(5.0 \mathrm{mmol})$ of BVEEB and $0.61 \mathrm{~g}(5.0 \mathrm{mmol})$ of PhVE in $33.3 \mathrm{~mL}$ of dichloromethane was added $30 \mu \mathrm{L}$ of $\mathrm{BF}_{3} \cdot \mathrm{OEt}_{2}$ in dichloromethane $\left(1.1 \mathrm{~mol} \mathrm{~L}^{-1}\right)$ at $0^{\circ} \mathrm{C}$. After $24 \mathrm{~h}$, the reaction mixture was poured into $200 \mathrm{~mL}$ of methanol. The methanol-insoluble product was separated, resolved into chloroform, and poured into methanol. After separating from methanol and drying in vacuum for $24 \mathrm{~h}, 0.97 \mathrm{~g}$ of the brittle copolymer was obtained (yield, 42\%). The molecular weight and the mole fraction of the BVEEB units are listed in Table I, and the ${ }^{1} \mathrm{H}$ NMR spectrum is shown in Figure 1.

\section{One-Plate Extraction}

The extraction of alkali-metal picrates was carried out using a procedure similar to the one developed by Pedersen. ${ }^{14}$ A solution of copolymer in dichloromethane ([crown ether units $]=3.5 \times 10^{-3} \mathrm{~mol} \mathrm{~L}^{-1}$ ) was vigorously shaken in a culture tube with an aqueous solution of alkali hydroxide and picric acid ([picric acid] $=7 \times 10^{-5} \mathrm{~mol} \mathrm{~L}^{-1}$, [alkali metal hydroxide $]=0.1 \mathrm{~mol} \mathrm{~L}^{-1}$ ). After the resulting two phases were separated, the alkali picrate extracted into the dichloromethane was indirectly determined by measuring the absorbance of picrate in the aqueous phase at $357 \mathrm{~nm}$ using a UV-spectrophotometer.

\section{RESULTS AND DISCUSSION}

For the homo- and copolymerization of $\alpha, \omega$-divinylethers, $\mathrm{CH}_{2} \mathrm{Cl}_{2}$ and $\mathrm{BF}_{3} \cdot \mathrm{OEt}_{2}$ are some of the most suitable solvents and catalysts for producing the gel-free polymers with crown ether units. ${ }^{3,4,11}$ In the present study, we also used this condition in order to prepare the copolymeric crown ethers. Table I lists the results of the copolymerizations of 1,2-bis[2(2-vinyloxyethoxy)ethoxy]benzene (BVEEB) with phenyl vinyl ether (PhVE), 4-methoxystyrene (MeOSt), and 9-vinylcarbazole ( $\mathrm{VCz}$ ), and, in order to compare them with those with isobutyl vinyl ether (IBVE). All the copolymerizations proceeded homogeneously and the resulting copolymers were soluble in chloroform and tetrahydrofuran. The copolymer yields for MeOSt and $\mathrm{VCz}$ were slightly high- 
Table I. Cationic cyclocopolymerization of 1,2-bis[2-(2-vinyloxyethoxy)ethoxy]benzene (BVEEB) with phenyl vinyl ether (PhVE), 4-methoxystyrene (MeOSt), 9-vinylcarbazole (VCz), and isobutyl vinyl ether (IBVE) ${ }^{\mathbf{a}}$

\begin{tabular}{|c|c|c|c|c|c|}
\hline Comonomer & $\begin{array}{l}\text { Mole fraction } \\
\text { of BVEEB } \\
\text { in monomers }\end{array}$ & $\frac{\text { Time }}{\mathrm{h}}$ & $\begin{array}{c}\text { Yield } \\
\% \%\end{array}$ & $\begin{array}{l}\text { Mole fraction } \\
\text { of BVEEB units } \\
\text { in copolymer }^{b}\end{array}$ & $M_{n}\left(M_{w} / M_{n}\right)^{\mathrm{c}}$ \\
\hline \multirow[t]{2}{*}{ PhVE } & 0.30 & 24 & 49 & 0.49 & 3900 (1.77) \\
\hline & 0.50 & 24 & 42 & 0.72 & 7400 (1.93) \\
\hline \multirow{2}{*}{ MeOSt } & 0.50 & 1 & 40 & 0.50 & $10600(1.74)$ \\
\hline & 0.65 & 24 & 77 & 0.66 & $9000(2.21)$ \\
\hline \multirow[t]{2}{*}{$\mathrm{VCz}$} & 0.50 & 0.2 & 61 & 0.48 & $12800(2.52)$ \\
\hline & 0.60 & 24 & 74 & 0.58 & $12300(2.66)$ \\
\hline \multirow[t]{2}{*}{ IBVE } & 0.42 & 24 & 50 & 0.47 & $15100(2.03)$ \\
\hline & 0.50 & 1 & 37 & 0.58 & $15600(2.22)$ \\
\hline
\end{tabular}

${ }^{a}$ Catalyst, $\mathrm{BF}_{3} \cdot \mathrm{OEt}_{2} ;\left[\mathrm{BF}_{3} \cdot \mathrm{OEt}_{2}\right]=1.0 \mathrm{mmol} \mathrm{L}^{-1} ; \quad[\mathrm{BVEEB}+\mathrm{comonomer}]=0.15 \mathrm{~mol} \mathrm{~L}-1 ;$ solvent, $\mathrm{CH}_{2} \mathrm{Cl}_{2}$; temp., $0^{\circ} \mathrm{C}$. ${ }^{b}$ Determined by ${ }^{1} \mathrm{H}$ NMR spectra. ${ }^{c}$ Determined by GPC using poly(styrene) standard.

er than those for PhVE and IBVE. The number-average molecular weights $\left(M_{n}\right)$ ranged from 3900 to 15600 and increased in the order of $\mathrm{PhVE} \ll \mathrm{MeOSt}<\mathrm{VCz}<\mathrm{IBVE}$.

Figure 1 shows the ${ }^{1} \mathrm{H}$ NMR spectra of the copolymers obtained from BVEEB with $\mathrm{PhVE}$, MeOSt, and $\mathrm{VCz}$ at the equimolar ratio of monomers. The characteristic absorptions at $6.36-6.59 \mathrm{ppm}$ due to the vinyloxy protons for BVEEB had completely disappeared as well as the copolymerization system with IBVE (Figure 1(d)), and thus BVEEB was polymerized with $100 \%$ cyclization. The copolymers obtained under other conditions also contained no residual vinyloxy bonds. The incorporation of the comonomer, PhVE, MeOSt, and $\mathrm{VCz}$, never inhibited the intramolecular cyclization of BVEEB. Since the cyclopolymerization of divinylether using a cationic initiator proceeded through a head-totail addition, the cyclic constitutional unit in the copolymer was benzo-19-crown-6. The copolymer compositions, which were determined by the ${ }^{1} \mathrm{H}$ NMR spectra, were similar to those in the monomer feeds for the copolymerization systems with $\mathrm{MeOSt}$ and $\mathrm{VCz}$. On the other hand, the mole fractions of BVEEB in the copolymer were larger than those in the monomer feeds for the system with

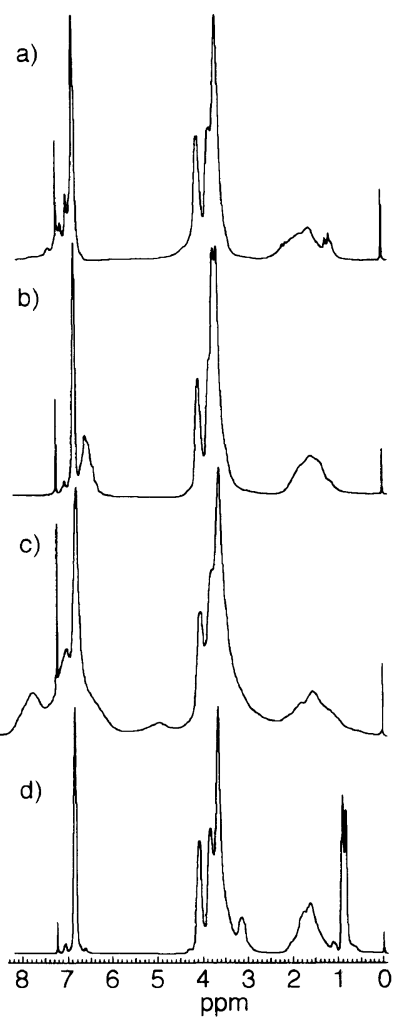

Figure 1. ${ }^{1} \mathrm{H}$ NMR spectra of the copolymers obtained from 1,2-bis[2-(2-vinyloxyethoxy)ethoxy]benzene (BVEEB) with a) phenyl vinyl ether (PhVE), b) 4-methoxystyrene (MeOSt), c) 9-vinylcarbazole ( $\mathrm{VCz}$ ), and d) isobutyl vinyl ether (IBVE). 
Table II. One-plate extraction of alkali-metal picrates by the copolymeric benzo-19-crown- ${ }^{\mathbf{a}}$

\begin{tabular}{|c|c|c|c|c|c|}
\hline \multirow{2}{*}{ Copolymeric benzo-19-crown-6 } & \multicolumn{5}{|c|}{ Extraction yield $(\%)$ of the picrate } \\
\hline & $\mathrm{Li}^{+}$ & $\mathrm{Na}^{+}$ & $\mathrm{K}^{+}$ & $\mathrm{Rb}^{+}$ & $\mathrm{Cs}^{+}$ \\
\hline Poly $\left[\left(\right.\right.$ benzo-19-crown-6) $\left.0.49-c o-\mathrm{PhVE}_{0.51}\right]$ & 3.2 & 44.9 & 76.5 & 85.9 & 81.2 \\
\hline Poly $\left[\left(\right.\right.$ benzo-19-crown-6) $0.50^{\left.-c o-\mathrm{MeOSt}_{0.50}\right]}$ & 1.1 & 45.3 & 77.9 & 86.5 & 80.0 \\
\hline Poly $\left[\left(\right.\right.$ benzo-19-crown-6) $\left.0.48-c o-\mathrm{VCz}_{0.52}\right]$ & 4.6 & 50.3 & 76.0 & 85.9 & 78.2 \\
\hline Poly $\left[\left(\right.\right.$ benzo-19-crown-6) $0.50^{-c o-I^{-}}$ & 4.6 & 34.0 & 71.0 & 68.0 & 84.0 \\
\hline
\end{tabular}

${ }^{a}$ Aqueous phase; $5 \mathrm{~mL}$ of aqueous solution of alkali hydroxide and picric acid ([alkali hydroxide] $=0.1 \mathrm{~mol} \mathrm{~L}^{-1}$ and [picric acid] $=7 \times 10^{-5} \mathrm{~mol} \mathrm{~L}^{-1}$ ). Organic phase; $5 \mathrm{~mL}$ of dichloromethane solution containing the copolymeric crown ether ([benzo-19-crown-6 units $\left.]=3.5 \times 10^{-3} \mathrm{~mol} \mathrm{~L}^{-1}\right)$. ${ }^{\mathrm{b}}$ Reference 11 .

PhVE, as well as the system with IBVE.

In order to study the binding properties of the copolymeric benzo-19-crown-6 toward $\mathrm{Li}^{+}, \mathrm{Na}^{+}, \mathrm{K}^{+}, \mathrm{Rb}^{+}$, and $\mathrm{Cs}^{+}$picrates, the copolymers with the copolymer composition of about 1:1 were used; poly[(benzo-19-crown$\left.6)_{0.49}-c o-\mathrm{PhVE}_{0.51}\right]$, poly[(benzo-19-crown$\left.6)_{0.50}-c o-\mathrm{MeOSt}_{0.50}\right]$, poly[(benzo-19-crown6) $\left.0.48 c o-\mathrm{VCz}_{0.52}\right]$, and poly [(benzo-19crown-6) $\left.0.4 \tau c o-\mathrm{IBVE}_{0.53}\right]$. The binding properties for each alkali cation picrate were obtained by the one-plate extraction experiment. Table II lists the extraction yields. For every copolymer, the yield for $\mathrm{Li}^{+}$was very low and that for $\mathrm{K}^{+}$was high, which agreed with the diameter of the benzo-19-crown-6 unit in the copolymers. On the other hand, the yields for $\mathrm{Rb}^{+}$and $\mathrm{Cs}^{+}$, which have diameters larger than the crown cavity, were also high. These results are explained by cooperative coordination effects, where two neighboring crown ether rings combine with a single cation. For the extracted alkali picrates, poly[(benzo-19crown-6) $\left.{ }_{0.49}-c o-\mathrm{PhVE}_{0.51}\right]$, poly[(benzo-19crown-6) $\left.)_{0.50}-\mathrm{co}-\mathrm{MeOSt}_{0.50}\right]$, and poly [(benzo19-crown-6) $\left.)_{0.48}-\mathrm{co}-\mathrm{VCz}_{0.52}\right]$ showed a similar selectivity in the order of $\mathrm{Rb}^{+}>\mathrm{Cs}^{+}>\mathrm{K}^{+} \gg$ $\mathrm{Na}^{+} \gg \mathrm{Li}^{+}$, which was different from that in the order of $\mathrm{Cs}^{+}>\mathrm{K}^{+}>\mathrm{Rb}^{+} \gg \mathrm{Na}^{+} \gg \mathrm{Li}^{+}$for poly[(benzo-19-crown-6) $\left.)_{0.4} \tau c o-\mathrm{IBVE}_{0.53}\right]$. This result means that the comonomer units in the copolymeric crown ethers affected the host-guest complexation. However we could not clarify the comonomer effect, for example, the bulkiness and the electro-donating property due to hetero atoms and aromatic rings, in the present study.

The cation-binding property of the polymeric benzo-19-crown-6 changed by varying the kind and the mole fraction of the comonomer units. ${ }^{11}$ For the utilization as a column filling agent and a membrane, therefore, one needs to design and prepare suitable copolymers according to each specific application.

\section{REFERENCES AND NOTES}

1. G. B. Butler and Q. S. Lien, "Cyclopolymerization and Polymer with Chain Ring Structure," ACS Symposium Series, No. 195, The American Chemical Society, Washington, D.C., 1982, p 145.

2. L. J. Mathias and J. B. Canterebrry, "Cyclopolymerization and Polymer with Chain Ring Structure," ACS Symposium Series, No. 195, The American Chemical Society, Washington, D.C., 1982, p 139.

3. K. Yokota, M. Matsumura, K. Yamaguchi, and Y. Takada, Makromol. Chem., Rapid Commun., 4, 721 (1983).

4. T Kakuchi, O. Haba, and K. Yokota, Macromolecules, 25, 4854 (1992).

5. T. Kakuchi, O. Haba, and K. Yokota, Makromol. Chem., 192, 1601 (1991) and references cited therein.

6. K. Yokota, H. Hashimoto, T. Kakuchi, and Y. Takada, Makromol. Chem., Rapid Commun., 5, 115 (1984).

7. H. Hashimoto, T. Kakuchi, and K. Yokota, Polym. Bull., 25, 153 (1991).

8. H. Hashimoto, T. Kakuchi, O. Haba, and K. Yokota, Macromolecules, 25, 1828 (1992). 


\section{T. KAKUCHI et al.}

9. J. Bartulin, M. Parra, A. Pamirez, and H. Zunza, Polym. Bull., 22, 33 (1989).

10. R. Rodenhouse, V. Percec, and A. E. Fering, $J$. Polym. Sci., C, Polym. Lett., 28, 345 (1990).

11. T. Kakuchi, K. Aoki, O. Haba, and K. Yokota, Polymer J., 25, 839 (1993).

12. T. Kakuchi, K. Aoki, O. Haba, and K. Yokota,
Polym. Bull., 31, 37 (1993).

13. T. Kakuchi, H. Hashimoto, Y. Harada, T. Satoh, and K. Yokota, J. Macromol. Sci., Pure and Applied Chemistry, A31, 751 (1994).

14. C. J. Pedersen, Fed. Proc., Fed. Am. Soc. Exp. Biol., 27, 1.305 (1968). 